\title{
Feasibility of nanoscale zero-valent iron loaded sediment-based biochar (nZVI-SBC) for simultaneous removal of nitrate and phosphate: high selectivity towards dinitrogen and synergistic mechanism
}

Xiaohui Liu

Beijing University of Technology

Jia Wei (D1320926263@qq.com )

Beijing University of Technology

Liangang Hou

Beijing University of Technology

Yuhan Zhu

Beijing University of Technology

Yaodong Wu

Beijing University of Technology

Luyi Xing

Beijing University of Technology

Yifei Zhang

Beijing University of Technology

Jun Li

Beijing University of Technology

\section{Research Article}

Keywords: Sediment-based biochar, Nanoscale zero-valent iron, Nitrate, Phosphate, Simultaneous removal

Posted Date: February 12th, 2021

DOl: https://doi.org/10.21203/rs.3.rs-222879/v1

License: (c) (i) This work is licensed under a Creative Commons Attribution 4.0 International License.

Read Full License 
Version of Record: A version of this preprint was published at Environmental Science and Pollution Research on March 13th, 2021. See the published version at https://doi.org/10.1007/s11356-021-13322w. 
Feasibility of nanoscale zero-valent iron loaded sediment-based biochar (nZVISBC) for simultaneous removal of nitrate and phosphate: high selectivity towards dinitrogen and synergistic mechanism

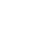
5

Xiaohui Liu, Jia Wei ${ }^{*}$, Liangang Hou, Yuhan Zhu, Yaodong Wu, Luyi Xing, Yifei

(1)

$$
\text { Zhang, Jun Li }
$$

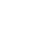

College of Architecture Engineering, Beijing University of Technology, 100

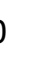

$$
\text { Pingleyuan, Chaoyang district, Beijing 100124, China. }
$$


25 Ethics approval and consent to participate: Not applicable.

26 Consent for publication: Not applicable. 1 42 43

Availability of data and materials: All data generated or analysed during this study are included in this published article and its supplementary information files.

Competing interests: The authors declare that they have no competing interests in this section.

Funding: All sources of funding for the research reported and The role of the funding body in the design of the study and collection, analysis, and interpretation of data and in writing the manuscript were declared in the manuscript.

\section{Authors' contributions}

X.H L. and J.W. designed the study, performed the research, analysed data, and wrote the paper. L.G. H., Y.H. Z., Y.D. W. and J. L. contributed significantly to analysis of the synergistic mechanism. L.Y. X. and Y.F. Z. helped perform the analysis with constructive discussions. All authors have read and approved the final manuscript.

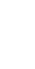
0 . (1) 


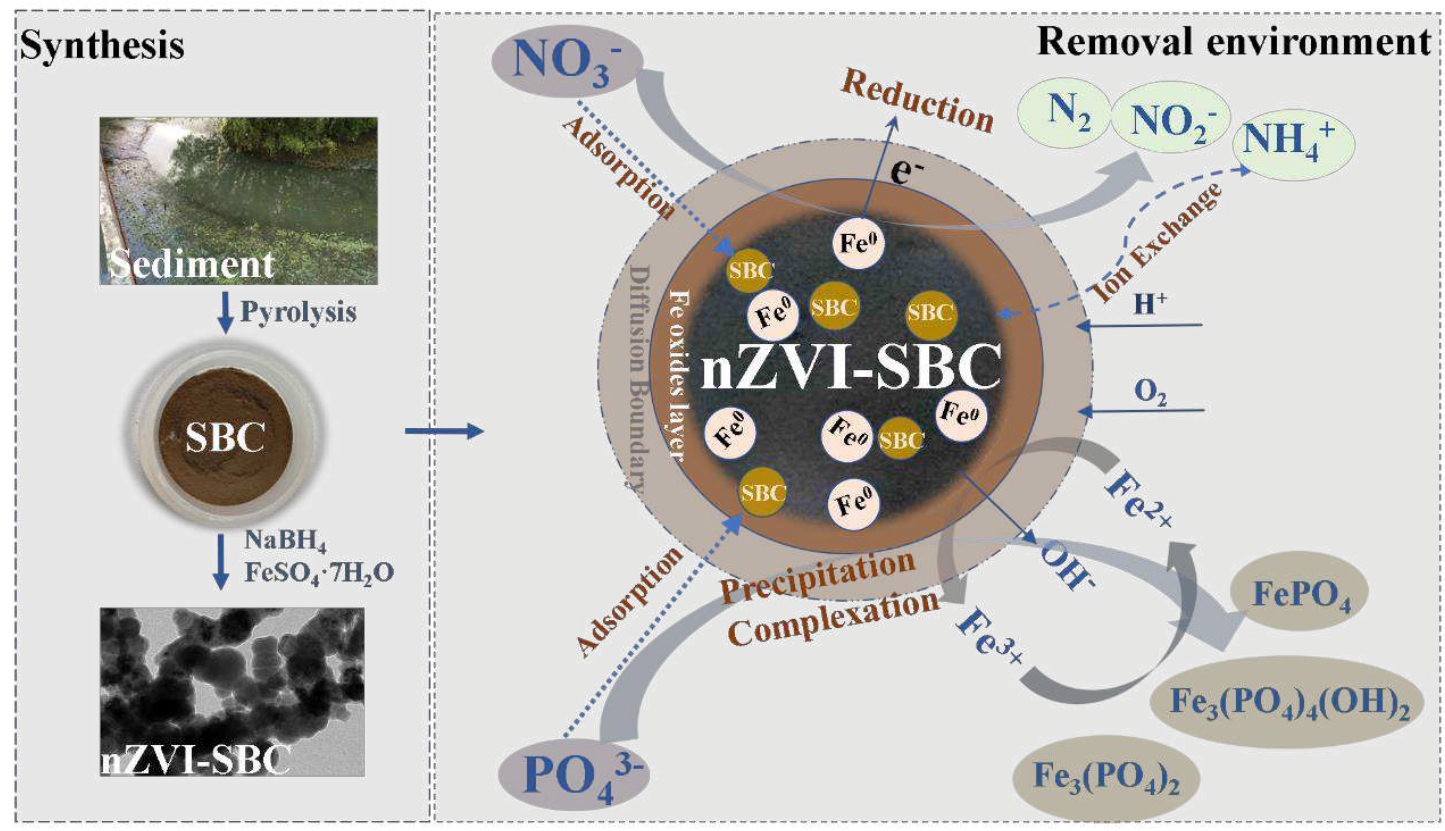

48 


\section{Abstract}

of great concern. Therefore, we prepared nanoscale zero-valent iron loaded on sediment-based biochar (nZVI-SBC) to conduct nitrate and phosphate removal at the same time. The characterization demonstrated that nZVI-SBC was successfully synthesized, which had obvious advantages for larger specific surface area and better dispersion compared with pure nZVI. The batch experiments indicated that the best loading ratio of $\mathrm{nZVI}$ to SBC and optimum dosage for nitrate and phosphate were 1:1 and $2 \mathrm{~g} \cdot \mathrm{L}^{-1}$, respectively. Their removal by $\mathrm{nZVI-SBC}$ was an acid-driven process. Anoxic environment was more conducive to the reduction of nitrate while the phosphate removal was fond of oxygen environment. $77.78 \%$ of nitrate and $99.21 \%$ of phosphate have been successfully removed, mainly depending on reduction and complexation mechanism, respectively. Moreover, nZVI-SBC had higher $\mathrm{N}_{2}$ selectivity and produced less ammonium than nZVI. The interaction between nitrate and phosphate was studied to manifest that they had different degrees of inhibition during the removal of the other. Our research indicated that nZVI-SBC has great potential for remediation of nitrogen and phosphorus polluted water.

Keywords: Sediment-based biochar; Nanoscale zero-valent iron; Nitrate; Phosphate;

\section{Simultaneous removal}

\section{Introduction}

Nitrogen $(\mathrm{N})$ and phosphorus $(\mathrm{P})$ are abundant in the water body because of human activities (Yin et al. 2018b). Eutrophication caused by nitrogen and phosphorus leads 
to water hypoxia, resulting in the death of a large number of fish and plants, thus affecting the water environment. In order to reduce the negative impacts of ecosystem overburden, researchers have developed many techniques for the treatment of water with high concentrations of nitrate and phosphate (e.g., ion exchange, filtration / reverse osmosis, biological process, chemical removal) (Oh et al. 2016). Chemical removal would be more economically viable, and fit for in-situ remediation of nitrate and phosphate from wastewater better compared with other methods.

Nanoscale zero-valent iron (nZVI) exhibits large active surface, high diffusion activation energy and strong quantum effect (Wang et al. 2019). Up to now, various contaminants including antibiotics, chlorinated organics, heavy metals, and dyes have already been effectively removed in nZVI-based processes (Diao et al. 2019). Due to the strong reduction, precipitation and complexation ability of nZVI, it has been also attempted to remove nitrate and phosphate. $98.9 \%$ of phosphate was removed from aqueous solution with nZVI (Wen et al. 2014), which suggested notably higher and better uptake of phosphate via nZVI in adsorption and coprecipitation processes. NZVI was also used to remove $39 \%$ of nitrate (Wei et al. 2018), indicating reducibility and tendency of aggregation of nZVI. However, the application of nZVI faces the challenges of thermodynamic instability, easy oxidation, short reaction duration, poor air stability and rapid agglomeration (Yang et al. 2018).

It is an effective strategy to promote the performance of nZVI by assembling suitable porous supports. Montmorillonite (Zhao et al. 2018), rectorite (Luo et al. 2013), bentonite (Diao et al. 2016), kaolinite (Li et al. 2016) and zeolite (He et al. 2018) are 
all reported as potential loaded materials. Biochar (BC) as a kind of powder material obtained by pyrolysis of biomass at high temperature in an oxygen-limited environment is paid close attention for high specific surface area, stable construction, and good electrical conductivity (Keiluweit et al. 2010). BC can adsorb pollutants and decrease their biological availability due to the interaction between functional groups (acidity/basicity) and electron transfer promoted by $\pi-\pi$ bond. These properties enable nZVI to adjust and optimize nanoparticles in the corrosion rate, dispersion, particle size, and electron transfer capacities (Jiang et al. 2018). The utilization of BC to support nZVI as a porous carrier enhances the reactivity of nZVI (Oleszczuk \&Koltowski 2017), prolongs its lifetime and improves the electron transfer efficiency (Cao et al. 2020). Furthermore, it is conducive to the resource recovery of biological waste and economically beneficial.

In the previous studies, many kinds of biomass materials such as corn stalks (Liu et al. 2018), cyanobacteria (Jiang et al. 2018), kenaf bark (Zhu et al. 2018), coconut shell and excess sludge (Wei et al. 2019) have been made into BC. However, BC made from river sediment is rarely studied. The sediments contain large number of biomass, which can be a novel choice to be used as raw materials for carbonization synthesis of BC (Yin et al. 2018a). Making biochar from sediment at high temperature not only avoids secondary pollution and land waste caused by sediment composting, ensuring the stability and harmlessness of sediment, but also benefits from lower cost and more reasonable economy compared with making sediment into filling materials, building materials and graded resource utilization. In addition, the composition of sediment is 
127

different from that of other biomass, which leads to great changes in its properties. In particular, its interaction with nZVI may vary greatly. As far as we know, few studies were related to sediment-based biochar and simultaneous removal of nitrate along with phosphate by nZVI-BC. Therefore, it brings great challenges to this research.

In this study, we took use of prepared sediment-based biochar (SBC) supported nZVI (nZVI-SBC) to synchronous removal of nitrate and phosphate and investigate synergistic affect between them. The research objectives were (1) to discover the specific properties of newly synthesized nZVI-SBC by a series of characterization methods, (2) to figure out the effects on removal of nitrate and phosphate, (3) to explore the mechanism of interrelation between nitrate and phosphate under the simultaneously removal by nZVI-SBC. The results of this study not only provide a better understanding of interaction between nitrate and phosphate commendably for us to optimize nZVIBC's application scenarios, but also show more possibilities for sediment resource utilization.

\section{Materials and methods}

\subsection{Preparation and characterization of nZVI-SBC}

The sediment was sampled from the esturary of the Tonghui River $\left(39^{\circ} 54^{\prime} 20^{\prime \prime} \mathrm{N}\right.$; $\left.116^{\circ} 33^{\prime} 11^{\prime \prime} \mathrm{E}\right)$, which is a polluted river connecting the Gaobeidian sewage treatment plant (Beijing, China). SBC was produced by $20 \mathrm{~g}$ of dry sediment under a 4-hourpyrolyzation at $400{ }^{\circ} \mathrm{C}$ in a muffle furnace with the protection of nitrogen. NZVI-SBC was obtained in one step by liquid phase reduction by $\mathrm{SBC}, \mathrm{FeSO}_{4} \cdot 7 \mathrm{H}_{2} \mathrm{O}$, and $\mathrm{NaBH}_{4}$ and further analyzed by of a series of characterization approaches including scanning 
electron microscopy (SEM), transmission electron microscopy (TEM), BrunauerEmmett-Teller (BET), X-ray diffraction (XRD), fourier transformation infrared spectroscopy (FTIR), X-ray photoelectron spectroscopy (XPS) and Zeta potentials. Supplementary material showed the details of materials and methods including preparation and characterization parameters of nZVI-SBC.

\subsection{Batch experiments}

The following nitrate and phosphate removal experiments were conducted in $50 \mathrm{~mL}$ sealed conical flask at $25^{\circ} \mathrm{C}$ with $160 \mathrm{rpm}$ shaking for $24 \mathrm{~h}$ to ensure equilibrium. After regular sampling and $0.22 \mu \mathrm{m}$ membrane filtration, the nitrate, nitrite, ammonium and phosphate concentration was analyzed. The average of the three replicate samples represented the reported measurements below.

Effects of operational parameters: Nitrate and phosphate solution were prepared at the initial concentration range of $20-100 \mathrm{mg} \cdot \mathrm{L}^{-1}$ and $5-50 \mathrm{mg} \cdot \mathrm{L}^{-1}$. Impacts of nZVISBC ratios $(1: 4,1: 2,1: 1,2: 1,4: 1)$, dosage of nZVI-SBC $\left(0.5-3.5 \mathrm{~g} \cdot \mathrm{L}^{-1}\right)$, initial $\mathrm{pH}\left(\mathrm{pH}_{i}\right)$ (3-11) and DO (0.3-9 $\left.\mathrm{mg} \cdot \mathrm{L}^{-1}\right)$ on the removal were examined in $25 \mathrm{~mL}$ solution (20 $\mathrm{NO}_{3}{ }^{-}-\mathrm{N} \mathrm{mg} \cdot \mathrm{L}^{-1}$ and $\left.5 \mathrm{PO}_{4}{ }^{3}-\mathrm{P} \mathrm{mg} \cdot \mathrm{L}^{-1}\right)$

Interaction of nitrate and phosphate: In order to inquire the influence of nitrate on phosphate removal under the action of nZVI-SBC, the $10 \mathrm{mg} \cdot \mathrm{L}^{-1}$ initial concentration of phosphate was controlled, and nitrate concentration was adjusted to $0,10,20,50$ and $100 \mathrm{mg} \cdot \mathrm{L}^{-1}$, respectively. Then, fixed $20 \mathrm{mg} \cdot \mathrm{L}^{-1}$ of nitrate was effected by phosphate concentration of $0,5,10,20$ and $50 \mathrm{mg} \cdot \mathrm{L}^{-1}$.

Kinetic experiment: The kinetic study was proceeded in the $25 \mathrm{~mL}$ nitrate and 
171 phosphate solution $\left(20 \mathrm{NO}_{3}{ }^{-}-\mathrm{N} \mathrm{mg} \cdot \mathrm{L}^{-1}, 5 \mathrm{PO}_{4}{ }^{3}-\mathrm{P} \mathrm{mg} \cdot \mathrm{L}^{-1}\right)$ and the samples were taken

172 out from conical flasks on the shaker one by one and filtered to be tested at the specified

173 time interval.

174 2.3. Analytical methods

175 During common nitrate reduction process, $\mathrm{NO}_{2}, \mathrm{~N}_{2}, \mathrm{NO}_{2}{ }^{-}, \mathrm{NH}_{4}{ }^{+}, \mathrm{NO}$ and $\mathrm{N}_{2} \mathrm{O}$ were 176 formed. As a matter of fact, the type of nitrate reduction products was strongly 177 dependent on the experimental conditions (Jung et al. 2014). The results showed that $178 \mathrm{NO}$ and $\mathrm{N}_{2} \mathrm{O}$ were generally formed under the condition of catalyst hydrogenation 179 (Liou et al. 2009). Hence, the production of $\mathrm{NO}_{\mathrm{x}}$ and $\mathrm{N}_{2} \mathrm{O}$ was assumed to be ignored. 180 We detected only $\mathrm{NO}_{2}^{-}$and $\mathrm{NH}_{4}{ }^{+}$in the solution and supposed that the rest products supplementary material.

\section{Results and discussion}


193

194

195

surface, which confirmed that nZVI had good dispersion on SBC. It showed that SBC could inhibit nZVI from agglomeration and improve its dispersion and valid reactivity. As for nZVI-SBC, C, O, Si and Fe were widely distributed in the whole region.

\subsubsection{XRD}

From the XRD images (Fig. 2), we could find that the stronger peak at $2 \theta=30.99^{\circ}$ was graphite crystal and the weaker diffraction peaks at $2 \theta=24.24^{\circ}, 25.66^{\circ}$ and $59.08^{\circ}$ were assigned to amorphous carbon structure as the typical characteristic for SBC and nZVI-SBC, indicating that the graphitization degree of SBC was relatively high. From the XRD analysis of nZVI-SBC, the higher peak at $2 \theta=52.14^{\circ}$ represented more $\mathrm{Fe}^{0}$ formed on the surface of SBC than pure nZVI. Peaks valued at $35.58^{\circ}\left(\mathrm{Fe}_{2} \mathrm{O}_{3}\right), 35.46^{\circ}$ $\left(\mathrm{Fe}_{3} \mathrm{O}_{4}\right)$ and $44.84^{\circ}\left(\mathrm{Fe}(\mathrm{OH})_{3}\right)$ confirmed a smaller portion of iron oxides and hydroxides produced in $\mathrm{Fe}^{0}$ oxidation during preparation or preservation. SBC played an important role in nZVI corrosion inhabitation.

\subsubsection{FTIR}

Fig. 3 showed the FTIR analysis of the functional groups of the synthesized materials from the wavelength range of 400 to $4000 \mathrm{~cm}^{-1}$. The stretching and bending vibration peaks of O-H could be found at the characteristic peaks near 1625 and 3423 $\mathrm{cm}^{-1}$ (Kayan et al. 2017), and the peaks at 1415 and $1436 \mathrm{~cm}^{-1}$ were attributed to the skeleton vibration peak of aromatic ring or $\mathrm{C}=\mathrm{C}$ vibration peak (Nguyen et al. 2015). The bands at 1030 and $1103 \mathrm{~cm}^{-1}$ were corresponding to $\mathrm{C}-\mathrm{O}$ stretching vibration. The bands at $462,467,778$ and $792 \mathrm{~cm}^{-1}$ went to the Si-O stretching vibration peak. The functional group types of SBC remained unchanged after loading nZVI. In the infrared 
spectra of nZVI and nZVI-SBC, the Fe-O stretching vibration peaks of $\mathrm{Fe}_{2} \mathrm{O}_{3}$ and $\mathrm{Fe}_{3} \mathrm{O}_{4}$ corresponded to the bands around 617 and $620 \mathrm{~cm}^{-1}$, indicating that nZVI was slightly oxidized (Li et al. 2017).

\subsubsection{XPS}

After XPS characterization, it can be seen that the functional organic group C-C, $\mathrm{C}=\mathrm{C}, \mathrm{C}-\mathrm{O}$ and $\mathrm{C}=\mathrm{O}$ contained on the surface of $\mathrm{SBC}$ still existed after loading (Fig. 4a, 4b). The differences between iron species of nZVI (Fig. 4c) and nZVI-SBC (Fig. 4d) surface were compared by XPS peak analysis. The results showed that the $\mathrm{Fe}^{0}$ area of nZVI and nZVI-SBC samples accounted for $6.20 \%$ and $9.70 \%$ respectively. There can be also observed less iron oxides assigned to $\mathrm{Fe}_{2} \mathrm{O}_{3}$ and $\mathrm{Fe}_{3} \mathrm{O}_{4}$ on the surface of nZVISBC than pure nZVI, which indicated that SBC could improve the stability of nano particles and inhibit the oxidation trend.

\subsubsection{Zeta potential}

The significance of Zeta potential is that the value is highly related to the material dispersion stability. Zeta potentials of nZVI and nZVI-SBC were shown in Fig. 5. At the same $\mathrm{pH}$ value, the isoelectric point of nZVI was higher at 7.42, and that of nZVISBC moved to 6.73 , indicating that electrostatic repulsion in nZVI-SBC particles was greater and the system was more stable (Sheng et al. 2015). Therefore, nZVI could be dispersed uniformly on SBC, and the aggregation tendency was weak.

\subsection{Effects of operating conditions on the removal}

\subsubsection{Effect of synthesis ratio of nZVI-SBC}

As BET analysis showed, SBC has a large surface area. However, the adsorption 
on biochar surface is mainly due to electrostatic interaction. Only $1.16 \%$ of nitrate was removed as the negative charged SBC rarely adsorbed nitrate anion as shown in Fig.6a. NZVI had more advantages in nitrate removal (33.30\%) than SBC due to its reducibility and adsorption capacity. Furthermore, compared with pure SBC and nZVI, the removal of nitrate by nZVI-SBC was significantly more improved, which effect was far better than that of SBC and nZVI alone. NZVI-SBC (1:1) had the highest removal efficiency of $77.78 \%$ among all nZVI-SBCs. Its superiority removal effect was mainly due to the more uniform distribution of iron particles and more active sites. The removal of phosphate was more easily. In addition to SBC's only $15.70 \%$ phosphate removal, the removal efficiency of other samples could reach more than $90 \%$.

\subsubsection{Effect of dosage of nZVI-SBC}

As Fig. $5 \mathrm{~b}$ depicted, with the increase of the dosage from $0.5 \mathrm{~g} \cdot \mathrm{L}^{-1}$ to $3.5 \mathrm{~g} \cdot \mathrm{L}^{-1}$, it had a positive correlation with nitrate and phosphate removal efficiency. Actually, as the dosage increased, more $\mathrm{Fe}^{0}$ active sites and adsorption space were provided, promoting nitrate reduction and adsorption. Especially, for phosphate, only $0.5 \mathrm{~g} \cdot \mathrm{L}^{-1}$ dosage could get $97.14 \%$ removal effect. However, the trend of removal rate and removal capacity varied with the change of dosage. For nitrate, the removal capacity reached the maximum of $7.778 \mathrm{mg} \cdot \mathrm{g}^{-1}$ when the dosage was $2 \mathrm{~g} \cdot \mathrm{L}^{-1}$ and then began to decline (Fig. S1). Therefore, the optimal dosage for this study was $2 \mathrm{~g} \cdot \mathrm{L}^{-1}$.

\subsubsection{Effect of initial $\mathrm{pH}$ in solution}

Effect of initial solution $\mathrm{pH}\left(\mathrm{pH}_{i}\right)$ on simultaneous removal by nZVI-SBC were explored from 3.0 to 11.0 in Fig.6c. Nitrate removal was highest under the most acidic 
conditions at $\mathrm{pH}_{i} 3$ (86.86\%). There was a slight decrease to $77.78 \%$ in a neutral environment at $\mathrm{pH}_{i} 7$ and a more severe drop of $34.70 \%$ at $\mathrm{pH}_{i} 11$. The removal efficiency was affected by the isoelectric point (about 6.73) to a great extent. The surface of nZVI-SBC was positively charged when the solution $\mathrm{pH}$ was lower than 6.73, and then negatively charged nitrate was easily adsorbed. Moreover, lower $\mathrm{pH}$ of solution would prevent the coating of ferrous hydroxide on the nZVI-SBC surface, yielding more nitrate reduction reaction sites. When the $\mathrm{pH}$ value of the solution was above the isoelectric point, the nitrate removal rate decreased due to the negative charge and electrostatic repulsion of nZVI-SBC. Then iron hydroxide precipitated in alkaline environment, leading to formation of a $\mathrm{Fe}(\mathrm{OH})_{2}$ and $\mathrm{Fe}(\mathrm{OH})_{3}$ layer deactivated the nZVI-SBC. It is worth noting that the $\mathrm{pH}$ of the solution increased to more than 8.0, and the final equilibrium $\mathrm{pH}$ was between 8.01 and 9.33 . The nitrate reduction process was $\mathrm{H}^{+}$consumption and $\mathrm{OH}^{-}$accumulation reaction. In addition, with the increase of $\mathrm{pH}_{i}$, the amount of ammonium reduced and nitrite accumulated slightly (Fig.S2).

The decrease of phosphate removal rate with increased $\mathrm{pH}_{i}$ was related to electrostatic repulsion as well. In addition, the surface protonation of nZVI-SBC was conducive to the complexation and coprecipitation reaction with phosphate under acidic conditions. During the reaction process, $\mathrm{Fe}^{3+}$ and $\mathrm{Fe}^{2+}$ on the surface of nZVI-SBC could form ferric hydroxide, then further co-precipitated with phosphate. To summarize, nitrate and phosphate removal by nZVI-SBC is an acid-driven process. However, both of them can achieve high removal rate and the conditions are more practical at $\mathrm{pH}_{i} 7$. Therefore, the following reactions are carried out at $\mathrm{pH}_{i} 7$. 


\subsubsection{Effect of dissolved oxygen concentrations}

The simulation of anaerobic to aerobic environment was carried out with different concentrations of DO from 0.3 to $9 \mathrm{mg} \cdot \mathrm{L}^{-1}$ in Fig. $6 \mathrm{~d}$. Anaerobic conditions are more beneficial to nitrate removal. Both $\mathrm{O}_{2}$ and nitrate could accept electron, but nZVI-SBC preferred $\mathrm{O}_{2}$ as an electron acceptor instead of nitrate. This yielded iron oxides forms, such as $\mathrm{Fe}_{3} \mathrm{O}_{4}, \mathrm{FeOOH}$ and $\mathrm{Fe}_{2} \mathrm{O}_{3}$ on the nZVI-SBC surface, which might drop the reactivity of nZVI and hinder further removal of nitrate over time. Additionally, Fig. S3 showed nitrite production after reaction equilibrium was very scarce under whether anaerobic or aerobic conditions. Nitrate was mainly converted into $\mathrm{N}_{2}$ and ammonium. However, there was a slight increase in phosphate removal with DO raised. As a result of low crystallinity and crystal defects of Fe, the increase of oxygen concentration accelerated the corrosion of nZVI and enhanced the complexation and coprecipitation of phosphate with iron.

3.3. The interaction between nitrate and phosphate

The increase of phosphate content was obviously disadvantageous to nitrate reduction (Fig.7a). This could be because the increased phosphate reacts with iron rapidly, forming an inner sphere complex on the surface of nZVI-SBC, resulting in the decrease of active sites and the hindrance of the contact of nZVI-SBC with nitrate. Nevertheless, the increase of phosphate concentration had little inhibition on the removal of phosphate (Fig.7b), and phosphate was able to achieve a good removal effect, which showed that phosphate and nZVI-SBC had a very strong ability of complex adsorption and coprecipitation. 

and phosphate was inhibited to different extent. As the number of active sites and adsorption centers of nZVI-SBC was limited, nitrate removal efficiency decreased (Fig.7c). As for phosphate, the increase of nitrate promoted the consumption of nZVI and $\mathrm{H}^{+}$, and the negative charge accumulated in the solution. Due to the electrostatic repulsion, it was not conducive to the adsorption of phosphate on the surface of the material. However, increased nitrate also made more nZVI form iron oxide and iron hydroxide. Phosphate could coprecipitate with more products, enhancing its removal. Obviously, the inhibition was stronger than promotion, so nitrate could inhibit the removal of phosphate in the reaction system(Fig.7d).

\subsection{Kinetics}

The experimental data of nitrate and phosphate removal were further revealed by the first-order and the second-order equations (Fig. 9a, 9b) (Wei et al. 2018). . The reaction equation was expressed in Eq. (1-2):

$317-\frac{\mathrm{d} C_{\mathrm{t}}}{d t}=k C_{\mathrm{t}}^{\mathrm{n}}$

$318 \quad \frac{1}{C_{\mathrm{t}}^{\mathrm{n}-1}}-\frac{1}{C_{0}^{\mathrm{n}-1}}=(n-1) k t$ evidence that the reaction was a first-order model reaction. The process required 
in the nitrate adsorption. The chemical reaction of nZVI-SBC to phosphate was more suitable for the second-order kinetic model due to its relatively higher $R^{2}$ than the firstorder kinetic model ( 0.997 versus 0.978$)$. The results indicated that the chemisorption was the dominant factor in the adsorption of phosphate by the nZVI-SBC. The reaction needed a shorter equilibrium time of $6 \mathrm{~h}$, and the constant was $0.047\left[(\mathrm{mg} \cdot \mathrm{L})^{1-\mathrm{n}} \cdot \mathrm{min}^{-1}\right]$.

\section{5. $\mathrm{N}_{2}$ selectivity}

Performance of nZVI and nZVI-SBC on $\mathrm{N}_{2}$ selectivity was studied. The $\mathrm{N}_{2}$ selectivity at equilibrium may be the result of competition between $\mathrm{NH}_{4}{ }^{+}$selectivity rate and $\mathrm{N}_{2}$ selectivity rate. The sum of generated $\mathrm{N}_{2}$ and adsorbed $\mathrm{NH}_{4}{ }^{+}$were recognized as an equivalent $\mathrm{N}_{2}$ selectivity. In the nZVI removal system, $94.31 \%$ of the reduced nitrate converted into ammonium, while only $4.32 \%$ accounted for $\mathrm{N}_{2}$. For nZVI-SBC, $41.77 \%$ and $57.14 \%$ of nitrate corresponded to ammonium and $\mathrm{N}_{2}$ respectively. Obviously, the nZVI-SBC exhibited higher $\mathrm{N}_{2}$ selectivity. The reduction of nitrate was a gradual process: firstly, nitrate was reduced to nitrite with $\mathrm{Fe}^{0}, \mathrm{Fe}^{2+}$ and other reducing agents, and then converted into $\mathrm{NH}_{4}{ }^{+}$or $\mathrm{N}_{2}$. Meanwhile, a micro battery with nZVI as anode and SBC as cathode could be formed spontaneously on nZVI-SBC materials, promoting the transfer of electrons to $\mathrm{NO}_{3}{ }^{-}$and accelerated the reduction. The relative potential difference could shorten intragranular diffusion resistance and drive the reduction of nitrite to $\mathrm{N}_{2}$. In addition, SBC could also be used as a good adsorbent for $\mathrm{NH}_{4}{ }^{+}$to improve $\mathrm{N}_{2}$ selectivity. NZVI-SBC could have a close $\mathrm{N}_{2}$ selectivity compared with metal-mixed nZVIs (Krasae \&Wantala 2016). However, supporting SBC was much cheaper and more realistic than those doped metals. Hence, 
347

the higher $\mathrm{N}_{2}$ selectivity by $\mathrm{nZVI-SBC}$ not only has important theoretical significance, but also huge potential economic benefit.

3.6. Nitrate and phosphate simultaneous removal mechanism

When nZVI particles were supported on SBC, they exhibited good dispersion, small particle size and high reaction activity. In addition, some $\mathrm{Fe}^{0}$ particles restricted or bound in the inner pore still remained active due to the microporous characteristics of SBC, despite the formation of iron oxide layer on nZVI-SBC. Moreover, SBC conducted electricity in oxidation and reduction reactions and provided conditions for diffusion and migration of molecules to iron active sites by promoting long-range electron transport.

The process of nitrate removal by nZVI involves the transfer of electrons between nZVI and the oxidizing species $\left(\mathrm{O}_{2}, \mathrm{H}^{+}\right.$, and nitrate) (Guan et al. 2015). The whole process of electron transfer usually involved a series of steps, including the migration of $\mathrm{O}_{2}, \mathrm{H}^{+}$, and nitrate from solution to nZVI-SBC surface, the reaction among them, and the diffusion of products $\left(\mathrm{Fe}^{3+}, \mathrm{Fe}^{2+}\right.$ and $\left.\mathrm{OH}^{-}\right)$into the solution. The removal process could be described via Eqs. (3)-(9). Furthermore, the micro battery formed spontaneously by SBC and nZVI accelerated the electron transfer and promoted the effective removal of nitrate. Ion exchange reaction could make $\mathrm{NH}_{4}^{+}$or nitrite products adsorbed by SBC, reducing nitrate to a greater extent and improving the selectivity of $\mathrm{N}_{2}$.

$\mathrm{Fe}^{0}+\mathrm{NO}_{3}{ }^{-}+2 \mathrm{H}^{+} \rightarrow \mathrm{Fe}^{2+}+\mathrm{NO}_{2}{ }^{-}+\mathrm{H}_{2} \mathrm{O}$

$$
3 \mathrm{Fe}^{0}+\mathrm{NO}_{2}{ }^{-}+8 \mathrm{H}^{+} \rightarrow 3 \mathrm{Fe}^{2+}+\mathrm{NH}_{4}{ }^{+}+2 \mathrm{H}_{2} \mathrm{O}
$$


369

370

371

372

373

374

375

376

377

378

379

380

381

382

$3 \mathrm{Fe}^{0}+2 \mathrm{NO}_{2}^{-}+8 \mathrm{H}^{+} \rightarrow 3 \mathrm{Fe}^{2+}+\mathrm{N}_{2}+4 \mathrm{H}_{2} \mathrm{O}$

$5 \mathrm{Fe}^{0}+2 \mathrm{NO}_{3}{ }^{-}+6 \mathrm{H}_{2} \mathrm{O} \rightarrow 5 \mathrm{Fe}^{2+}+\mathrm{N}_{2}+12 \mathrm{OH}^{-}$

$\mathrm{Fe}^{0}+2 \mathrm{H}_{2} \mathrm{O} \rightarrow \mathrm{Fe}^{2+}+\mathrm{H}_{2}+2 \mathrm{OH}^{-}$

$\mathrm{NO}_{3}{ }^{-}+2 \mathrm{H}^{+}+4 \mathrm{H}_{2} \rightarrow \mathrm{NH}_{4}{ }^{+}+3 \mathrm{H}_{2} \mathrm{O}$

$4 \mathrm{Fe}^{0}+\mathrm{NO}_{3}{ }^{-}+10 \mathrm{H}^{+} \rightarrow 4 \mathrm{Fe}^{2+}+\mathrm{NH}_{4}{ }^{+}+3 \mathrm{H}_{2} \mathrm{O}$

Phosphate could be significantly removed by nZVI-SBC. The mechanism of phosphate removal contained adsorption, complexation and coprecipitation. As mentioned in 3.2.3, the process of complexation and precipitation might play a major role, while the electrostatic attraction mechanism was not dominant in alkaline environment. As a result of the reaction between iron and water, a layer of hydroxide including $\mathrm{Fe}(\mathrm{OH})_{2}, \mathrm{Fe}(\mathrm{OH})_{3}, \mathrm{FePO}_{4}, \mathrm{Fe}_{3}\left(\mathrm{PO}_{4}\right)_{2}$ and $\mathrm{Fe}_{3}\left(\mathrm{PO}_{4}\right)_{4}(\mathrm{OH})_{2}$ (Fig. S4.) was formed at the same time.

The adsorption, reduction, coprecipitation and complexation coexisted in the removal process, but the four kinds of functions also affected each other in various ways. Due to the limited attachment site and activity of nanomaterials, nitrate and phosphate had different inhibition on each other's removal. However, nZVI-SBC could have ideal removal effects for both.

\section{Conclusions}

In this study, we have successfully synthesized and used SBC as the carrier of nZVI for simultaneous removal of nitrate and phosphate. SBC could significantly inhibit the aggregation tendency of particles and prevent them from passivation. Nitrate and phosphate removal were both favorable in acidic environment. Nitrate removal was 
391

392

more efficient under anaerobic conditions, but phosphate preferred oxygen. NZVI-SBC mainly took advantage of its strong reducibility to fully remove nitrate, while the removal of phosphate depended on its complexation and co-precipitation with iron oxide and hydroxide. Nitrate and phosphate coexisted and antagonized each other, and finally reached a state of dynamic equilibrium. The micro battery formed by nZVI/SBC had the functions of redox, precipitation, adsorption and electrochemical capture.

They all played an important role in the removal of target pollutants. Moreover, nZVISBC showed higher $\mathrm{N}_{2}$ selectivity and less ammonium production than nZVI. The proposed synchronous removal process showed significant application potential for sediment-based biochar, which broadened the perspective for us to select adsorption materials, and successfully achieved the resource utilization of biomass waste. Furthermore, the successful combination of SBC and nZVI also had certain reference significance for water treatment.

\section{Acknowledgements}

Authors would like to acknowledge the financial support by the National Natural Science Foundation of China (51778015), Beijing Municipal Natural Science Foundation (8202007) and Major Science and Technology Program for Water Pollution Control and Treatment (2017ZX07103-001).

\section{References}

Cao Z, Li H, Xu XH, Xu J (2020): Correlating surface chemistry and hydrophobicity of sulfidized nanoscale zerovalent iron with its reactivity and selectivity for 
denitration and dechlorination. Chem. Eng. J. 394, 124876. https://doi.org/10.1016/j.cej.2020.124876

Diao ZH, Xu XR, Jiang D, Kong LJ, Sun YX, Hu YX, Hao QW, Chen H (2016): Bentonite-supported nanoscale zero-valent iron/persulfate system for the simultaneous removal of $\mathrm{Cr}(\mathrm{VI})$ and phenol from aqueous solutions. Chem. Eng. J. 302, 213-222. https://doi.org/10.1016/j.scitotenv.2019.01.037

Diao ZH, Qian W, Lei ZX, Kong LJ, Du JJ, Liu H, Yang JW, Pu SY (2019): Insights on the nitrate reduction and norfloxacin oxidation over a novel nanoscale zero valent iron particle: Reactivity, products, and mechanism. Sci. Total Environ. 660, 541-549. https://doi.org/10.1016/j.cej.2016.05.062

Guan XH, Sun YK, Qin HJ, Li JX, Lo IMC, He D, Dong HR (2015): The limitations of applying zero-valent iron technology in contaminants sequestration and the corresponding countermeasures: the development in zero-valent iron technology in the last two decades (1994-2014). Water Res. 75, 224-248. https://doi.org/10.1016/j.watres.2015.02.034

He YH, Lin H, Dong YB, Li B, Wang L, Chu SY, Luo MK, Liu JF (2018): Zeolite supported $\mathrm{Fe} / \mathrm{Ni}$ bimetallic nanoparticles for simultaneous removal of nitrate and phosphate: Synergistic effect and mechanism. Chem. Eng. J. 347, 669-681. https://doi.org/10.1016/j.cej.2018.04.088

Jiang XY, Ouyang ZZ, Zhang ZF, Yang C, Li XQ, Dang Z, Wu PX (2018): Mechanism of glyphosate removal by biochar supported nano-zero-valent iron in aqueous solutions. Colloids Surf., A 547, 64-72. https://doi.org/10.1016/j.colsurfa.2018.03.041

Jung SY, Bae SJ, Lee WJ (2014): Development of Pd-Cu/Hematite Catalyst for Selective Nitrate Reduction. Environ. Sci. Technol. 48, 9651-9658. https://doi.org/10.1021/es502263p

Kayan B, Khataee A, Kalderis D, Akay S, Konsolakis M (2017): Ultrasound-assisted removal of Acid Red 17 using nanosized Fe3O4-loaded coffee waste hydrochar. Ultrason. Sonochem. 35, 72-80. https://doi.org/10.1016/j.ultsonch.2016.09.004 
Keiluweit M, Nico PS, Johnson MG, Kleber M (2010): Dynamic Molecular Structure of Plant Biomass-Derived Black Carbon (Biochar). Environ. Sci. Technol. 44, 1247-1253. https://doi.org/10.1021/es9031419

Krasae N, Wantala K (2016): Enhanced nitrogen selectivity for nitrate reduction on CunZVI by TiO2 photocatalysts under UV irradiation. Appl. Surf. Sci. 380, 309317. https://doi.org/10.1016/j.apsusc.2015.12.023

Li PJ, Lin KR, Fang ZQ, Wang KM (2017): Enhanced nitrate removal by novel bimetallic Fe/Ni nanoparticles supported on biochar. J. Cleaner Prod. 151, 2133. https://doi.org/10.1016/j.jclepro.2017.03.042

Li XG, Zhao Y, Xi BD, Mao XH, Gong B, Li R, Peng X, Liu HL (2016): Removal of Nitrobenzene by Immobilized Nanoscale Zero-valent Iron: Effect of Clay Support and Efficiency Optimization. Appl. Surf. Sci. 370, 260-269 https://doi.org/10.1016/j.apsusc.2016.01.141

Liou YH, Lin CJ, Weng SC, Ou HH, Lo SL (2009): Selective Decomposition of Aqueous Nitrate into Nitrogen Using Iron Deposited Bimetals. Environ. Sci. Technol. 43, 2482-2488. https://doi.org/10.1021/es802498k

Liu CM, Diao ZH, Huo WY, Kong LJ, Du JJ (2018): Simultaneous removal of Cu (2+) and bisphenol A by a novel biochar- supported zero valent iron from aqueous solution: Synthesis, reactivity and mechanism. Environ. Pollut. 239, 698-705. https://doi.org/10.1016/j.envpol.2018.04.084

Luo S, Qin PF, Shao JH, Peng L, Gu JD (2013): Synthesis of reactive nanoscale zero valent iron using rectorite supports and its application for Orange II removal. Chem. Eng. J. 223, 1-7. https://doi.org/10.1016/j.cej.2012.10.088

Nguyen TC, Loganathan P, Nguyen TV, Vigneswaran S, Kandasamy J, Naidu R (2015): Simultaneous adsorption of $\mathrm{Cd}, \mathrm{Cr}, \mathrm{Cu}, \mathrm{Pb}$, and $\mathrm{Zn}$ by an iron-coated Australian zeolite in batch and fixed-bed column studies. Chem. Eng. J. 270, 393-404. https://doi.org/10.1016/j.cej.2015.02.047

Oh SY, Seo YD, Kim B, Kim IY, Cha DK (2016): Microbial reduction of nitrate in the presence of zero-valent iron and biochar. Bioresour. Technol. 200, 891-896. http://dx.doi.org/10.1016/j.biortech.2015.11.021 
Oleszczuk P, Koltowski M (2017): Effect of co-application of nano-zero valent iron and biochar on the total and freely dissolved polycyclic aromatic hydrocarbons removal and toxicity of contaminated soils. Chemosphere 168, 1467-1476. https://doi.org/10.1016/j.chemosphere.2016.11.100

Sheng G, Alsaedi A, Shammakh W, Monaquel S, Huang Y (2015): Enhanced sequestration of selenite in water by nanoscale zero valent iron immobilization on carbon nanotubes by a combined batch, XPS and XAFS investigation. Carbon 99, 123-130. https://doi.org/10.1016/j.carbon.2015.12.013

Wang S, Zhao M, Zhou M, Li YC, Wang J, Gao B, Sato S, Feng K, Yin W, Igalavithana AD, Oleszczuk P, Wang X, Ok YS (2019): Biochar-supported nZVI (nZVI/BC) for contaminant removal from soil and water: A critical review. J. Hazard. Mater 373, 820-834. https://doi.org/10.1016/j.jhazmat.2019.03.080

Wei Al, Ma J, Chen Jj, Zhang Y, Song JX, Yu XY (2018): Enhanced nitrate removal and high selectivity towards dinitrogen for groundwater remediation using biochar-supported nano zero-valent iron. Chem. Eng. J. 353, 595-605. https://doi.org/10.1016/j.cej.2018.07.127

Wei J, Liu YT, Li J, Zhu YH, Yu H, Peng YZ (2019): Adsorption and co-adsorption of tetracycline and doxycycline by one-step synthesized iron loaded sludge biochar. Chemosphere 236, 124254. https://doi.org/10.1016/j.chemosphere.2019.06.224

Wen Z, Zhang Y, Dai C (2014): Removal of phosphate from aqueous solution using nanoscale zerovalent iron (nZVI). Colloids Surf., A 457, 433-440. https://doi.org/10.1016/j.colsurfa.2014.06.017

Yang F, Zhang S, Sun Y, Cheng K, Li J, Tsang DCW (2018): Fabrication and characterization of hydrophilic corn stalk biochar-supported nanoscale zerovalent iron composites for efficient metal removal. Bioresour. Technol. 265, 490-497. https://doi.org/10.1016/j.biortech.2018.06.029

Yin HB, Zhu JC, Tang WY (2018a): Management of nitrogen and phosphorus internal loading from polluted river sediment using Phoslock ${ }^{\circledR}$ and modified zeolite with intensive tubificid oligochaetes bioturbation. Chem. Eng. J. 353, 46-55. https://doi.org/10.1016/j.cej.2018.07.112 
504 Yin Q, Ren H, Wang R, Zhao Z (2018b): Evaluation of nitrate and phosphate adsorption on Al-modified biochar: Influence of Al content. Sci. Total Environ. 631-632, 895-903. https://doi.org/10.1016/j.scitotenv.2018.03.091 (2018): Montmorillonite supported nanoscale zero-valent iron immobilized in sodium alginate (SA/Mt-NZVI) enhanced the nitrogen removal in vertical flow constructed wetlands (VFCWs). Bioresour. Technol. 267, 608-617. https://doi.org/10.1016/j.biortech.2018.07.072

Zhu YE, Hua L, Zhang GX, Meng FJ, Li LF, Wu S (2018): Removal of hexavalent chromium from aqueous solution by different surface-modified biochars: Acid washing, nanoscale zero-valent iron and ferric iron loading. Bioresour. Technol. 261, 142-150. https://doi.org/10.1016/j.biortech.2018.04.004

516 


\section{Figures}

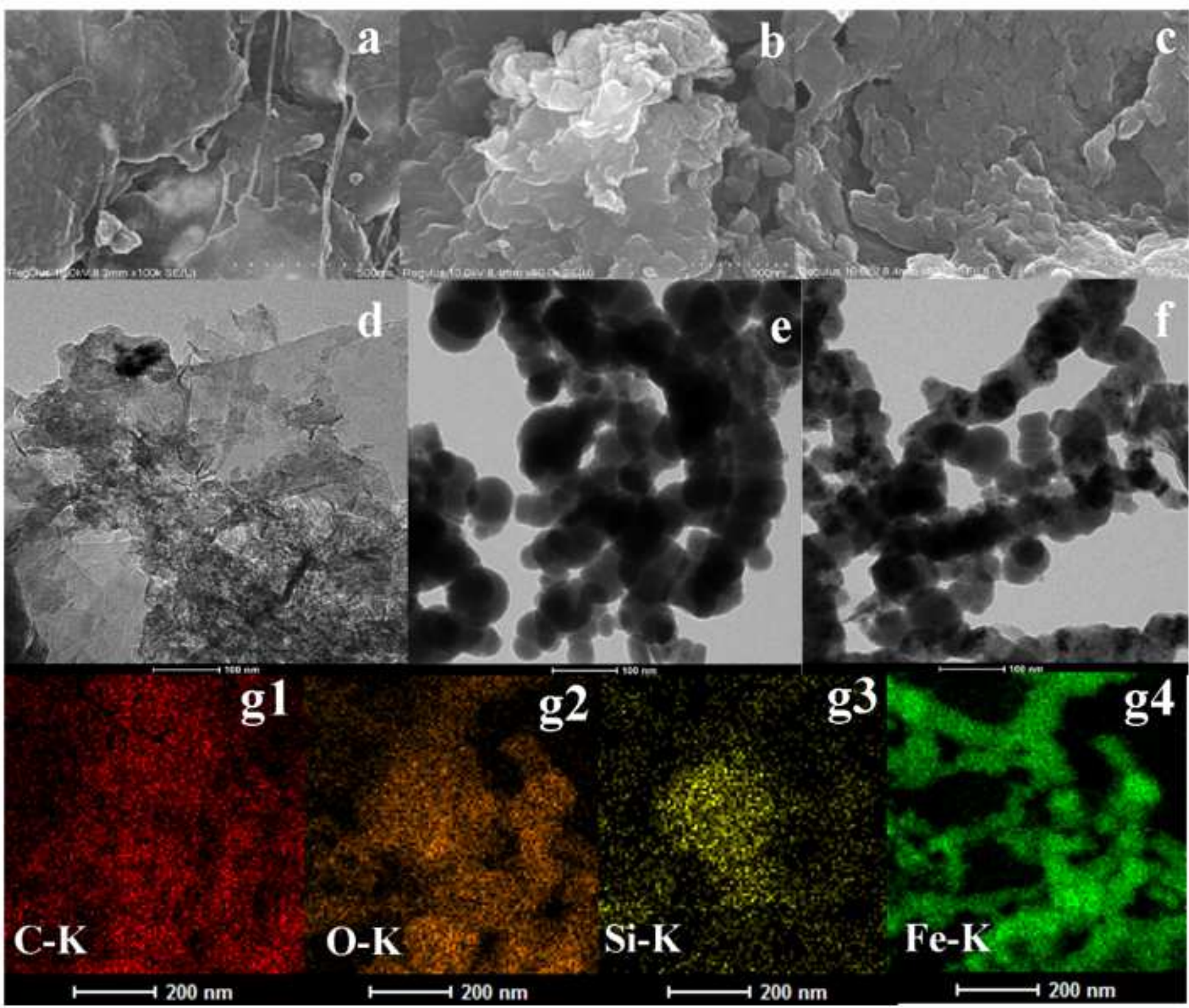

\section{Figure 1}

Electron microscope images and elemental mapping (a. SEM of pristine sediment; b. SEM of SBC; c. SEM of nZVI-SBC; d. TEM of SBC; e. TEM of nZVl; f. TEM of nZVI-SBC; g. elemental mapping of nZVI-SBC). 


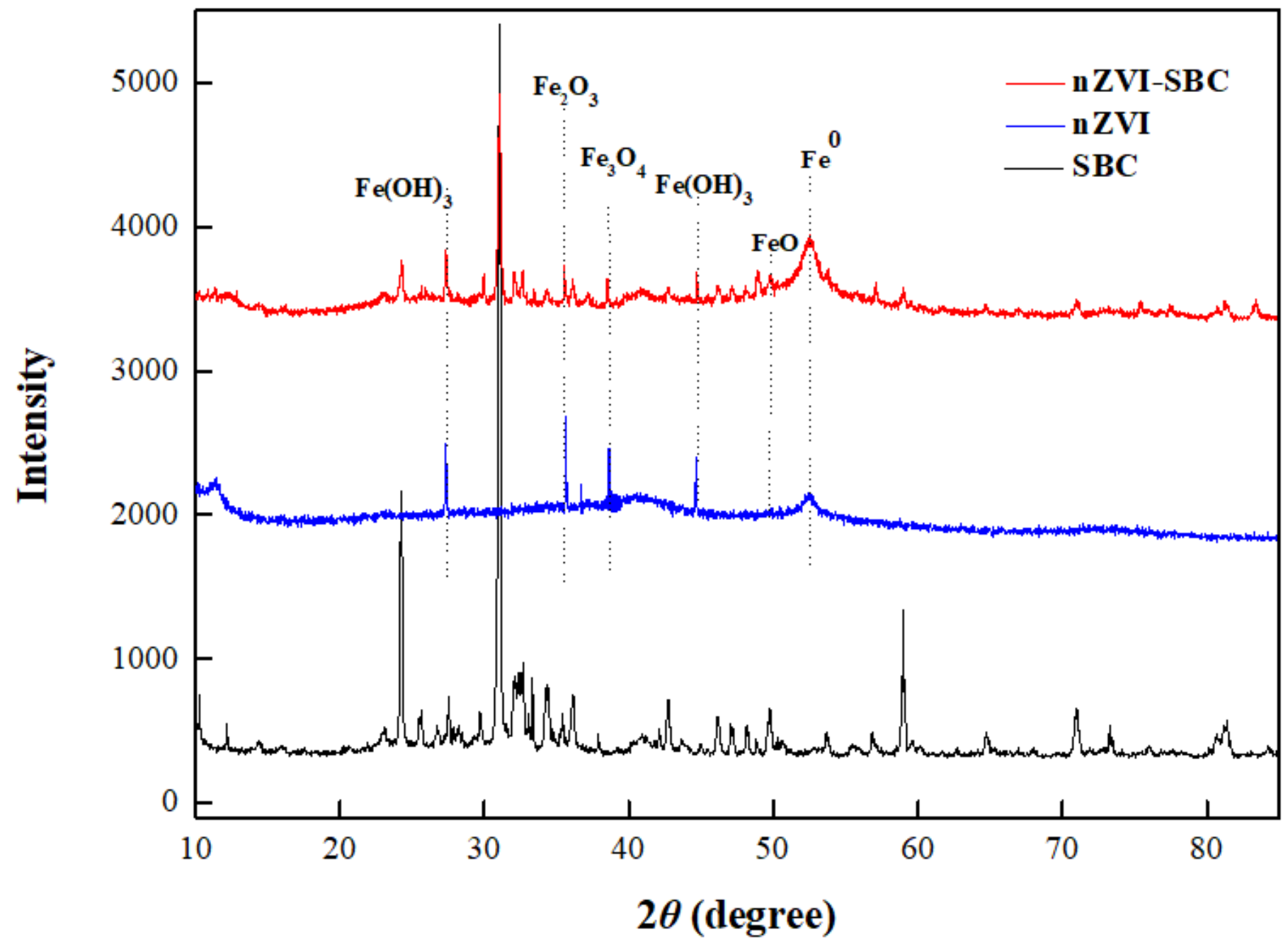

Figure 2

X-ray diffraction patterns of SBC, nVZI-SBC and nZVI. 


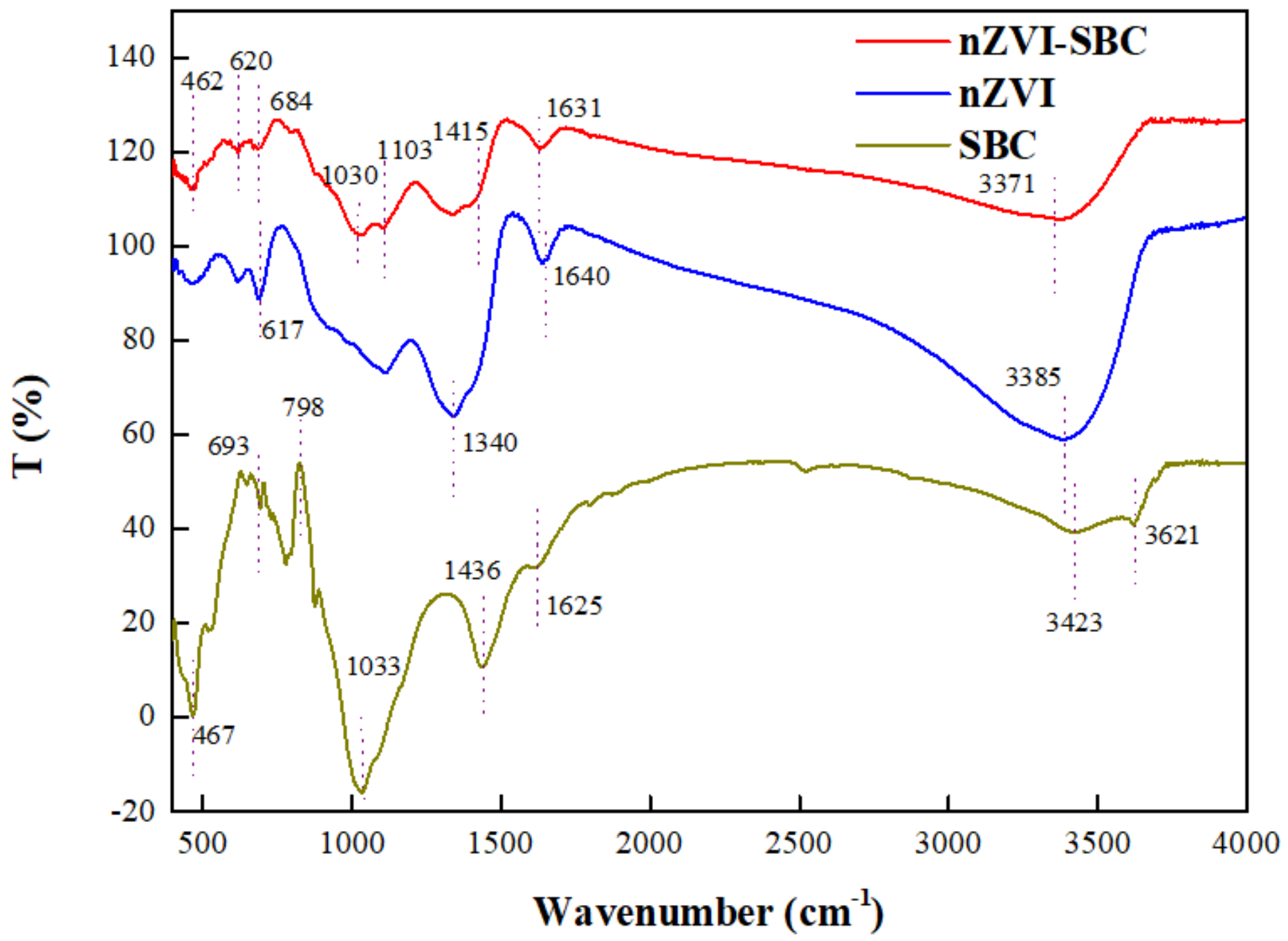

Figure 3

Fourier transform infrared spectra (a. SBC; b. nZVI-SBC; c. nZVI). 

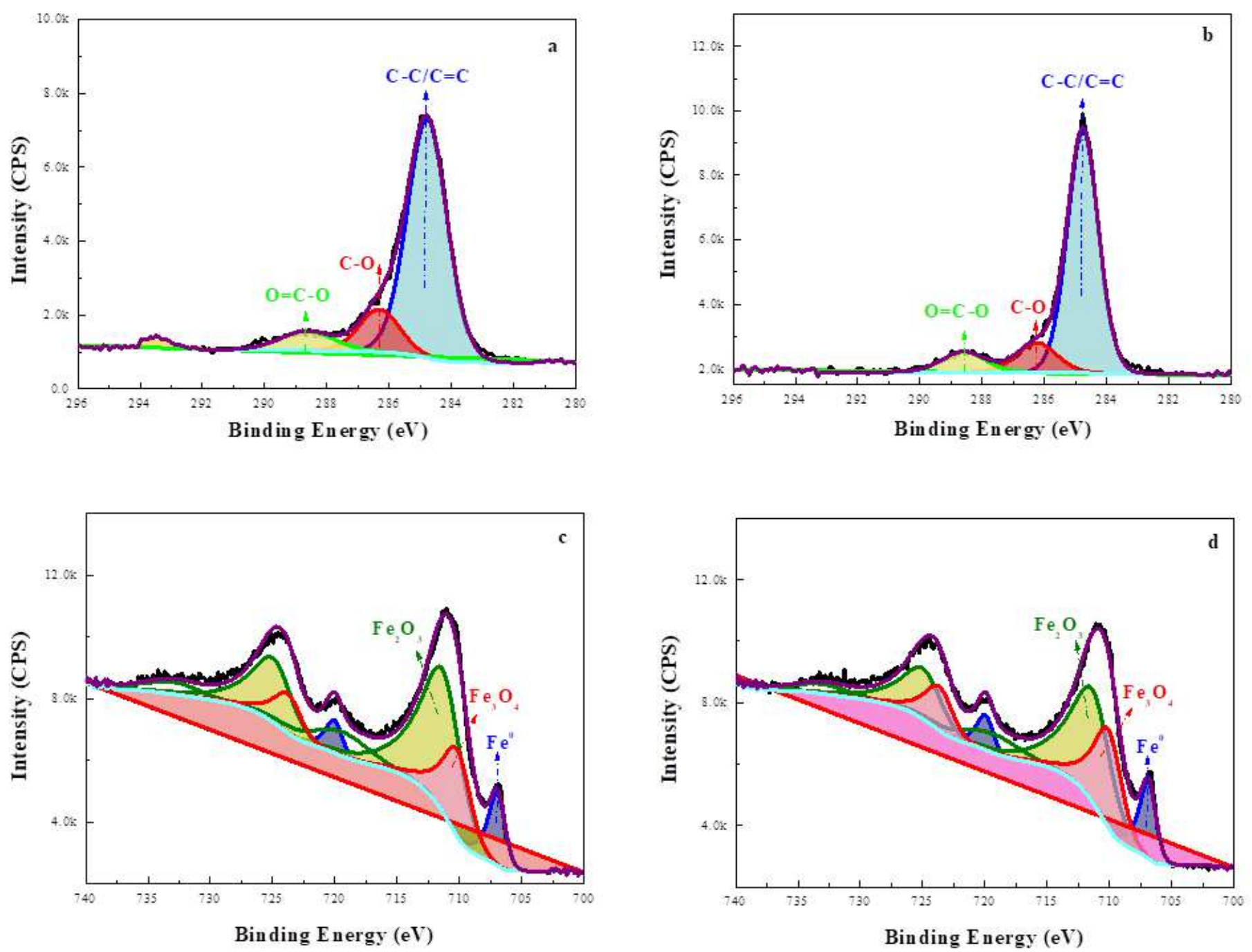

Figure 4

XPS images of C, $\mathrm{O}$ analysis (a. SBC; b. nZVI-SBC) and Fe analysis (c. nZVI; d. nZVI-SBC. 


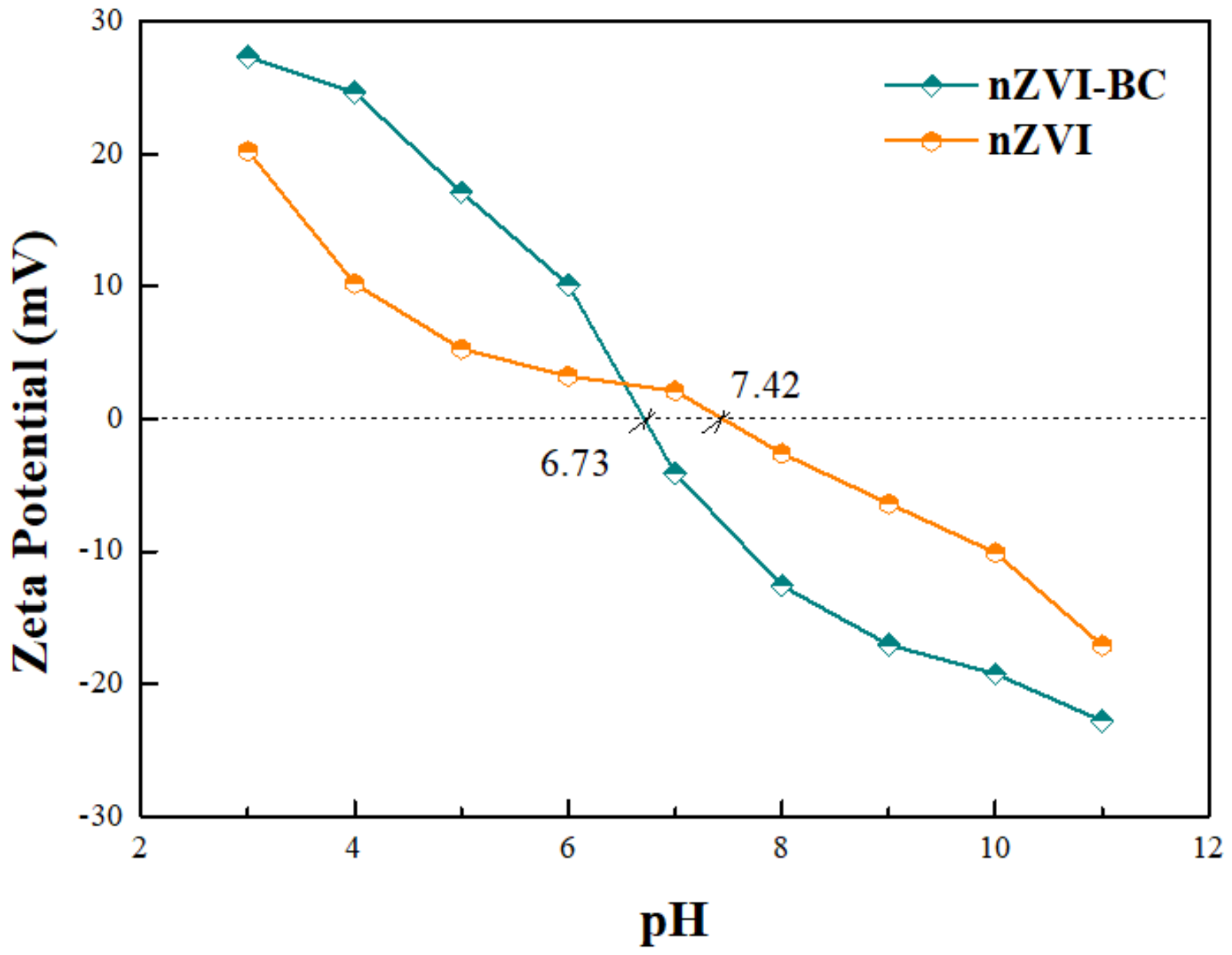

Figure 5

Zeta potential of nZVI-SBC and nZVI. 

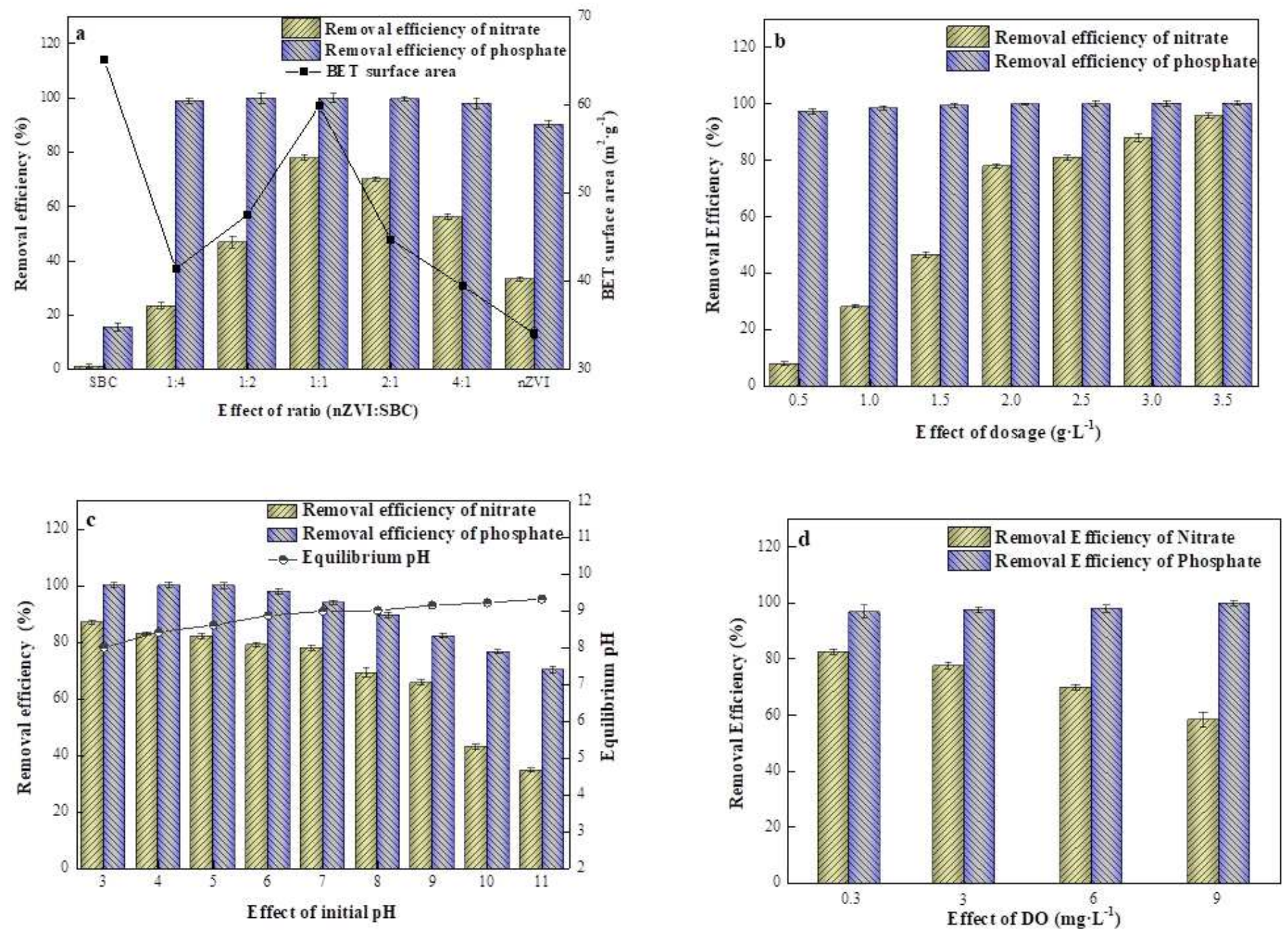

Figure 6

Effects on the removal of nitrate and phosphate (20 NO3--N mg.L-1, 5 PO43-P mg.L-1): a. mass ratio of $\mathrm{Fe} 0(\mathrm{pH}=7, \mathrm{DO}=3 \mathrm{mg} \cdot \mathrm{L}-1$, dosage $=2 \mathrm{~g} \cdot \mathrm{L}-1) ;$ b. dosage $(\mathrm{pH}=7, \mathrm{DO}=3 \mathrm{mg} \cdot \mathrm{L}-1) ; \mathrm{c}$. initial solution $\mathrm{pH}$ (dosage $=2 \mathrm{~g} \cdot \mathrm{L}-1, \mathrm{DO}=3 \mathrm{mg} \cdot \mathrm{L}-1) ; \mathrm{d}$. DO (dosage = $2 \mathrm{~g} \cdot \mathrm{L}-1, \mathrm{pH}=7)$. 

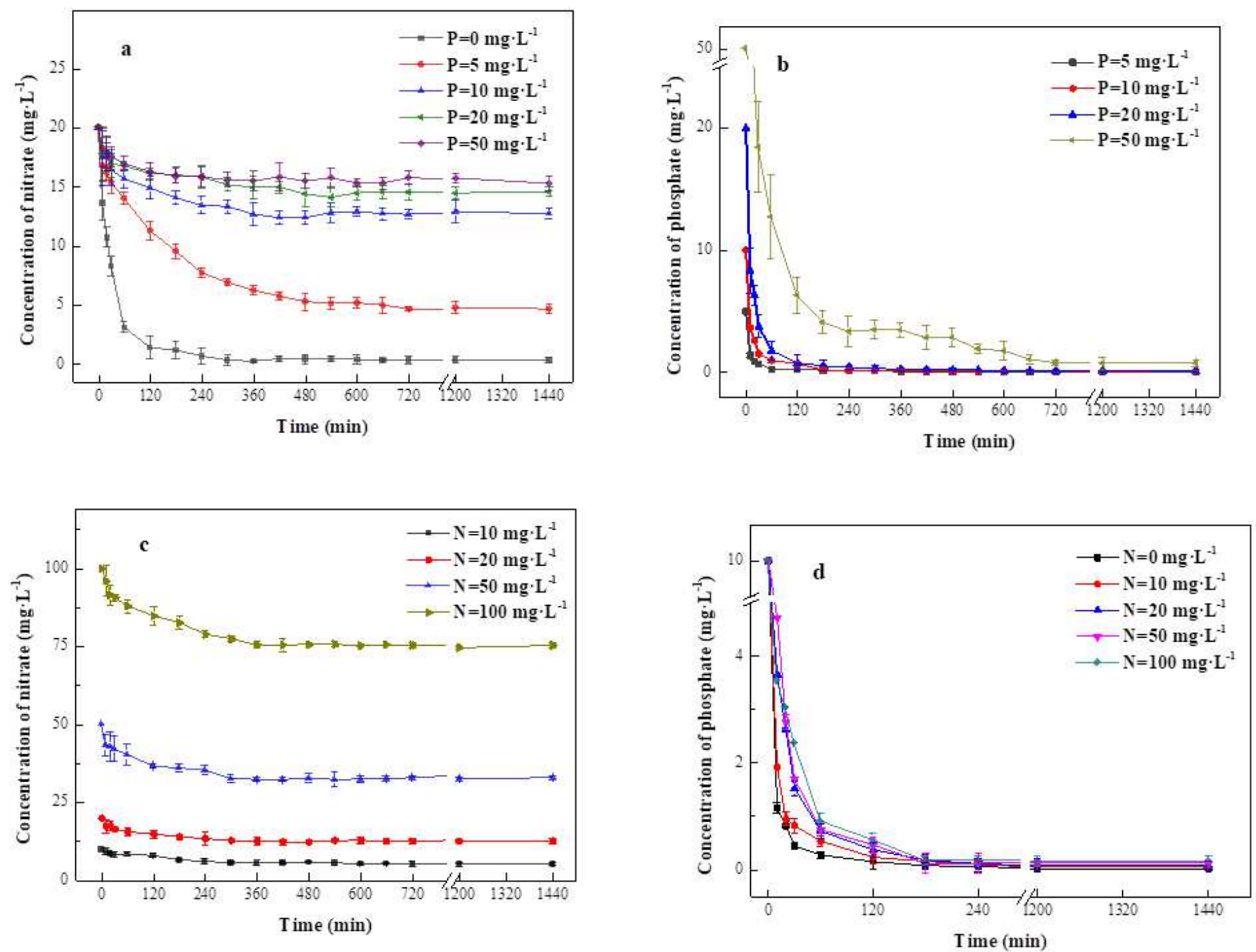

Figure 7

The influence of phosphate concentration (dosage $=2 \mathrm{~g} \cdot \mathrm{L}-1, \mathrm{pH}=7, \mathrm{DO}=3 \mathrm{mg} \cdot \mathrm{L}-1$ ): $\mathrm{a}$. nitrate removal, $\mathrm{b}$. phosphate removal; the influence of nitrate concentration (dosage $=2 \mathrm{~g} \cdot \mathrm{L}-1, \mathrm{pH}=7, \mathrm{DO}=3 \mathrm{mg} \cdot \mathrm{L}-1$ ): $\mathrm{C}$. nitrate removal, d. phosphate removal. 

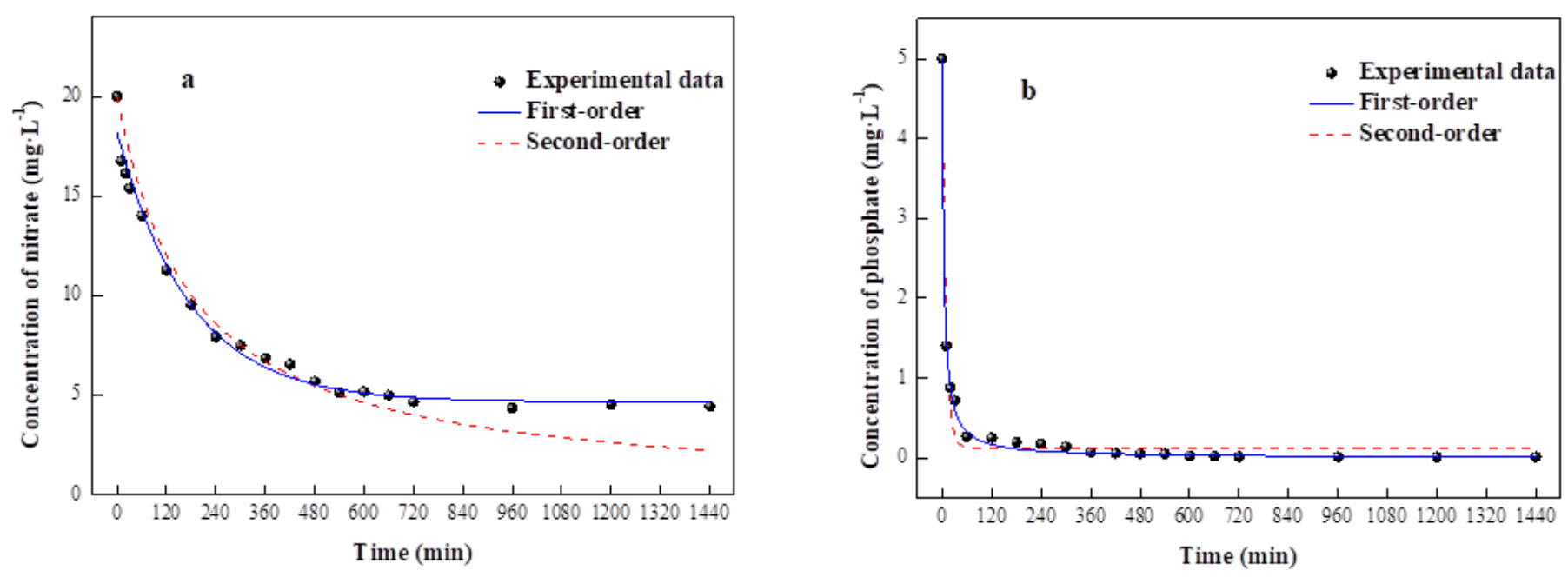

Figure 8

Kinetics of nitrate (a) and phosphate (b) removal (20 NO3--N mg.L-1, 5 P043-P mg.L-1, dosage $=2 \mathrm{~g} \cdot \mathrm{L}-1$, $\mathrm{pH}=7, \mathrm{DO}=3 \mathrm{mg} \cdot \mathrm{L}-1)$.

\section{Supplementary Files}

This is a list of supplementary files associated with this preprint. Click to download.

- Graphicalabstract.png

- Supplementarymaterial.docx 